\title{
Akut karın ağrısında nadir bir sebep: ince bağırsak adenokarsinomu
}

\section{A rare cause of acute abdominal pain: small intestine adenocarcinoma}

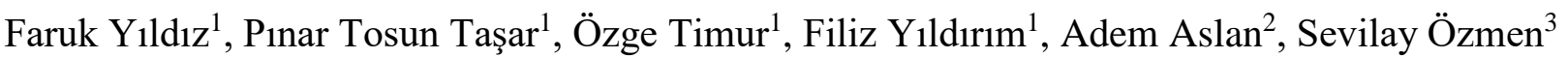 \\ ${ }^{1}$ İç Hastalıkları Kliniği, Erzurum Bölge Eğitim ve AraştırmaHastanesi, Erzurum, Türkiye \\ ${ }^{2}$ Genel Cerrahi Kliniği, Erzurum Bölge Eğitim ve AraştırmaHastanesi, Erzurum, Türkiye \\ ${ }^{3}$ Tıbbi Patoloji Kliniği, Erzurum Bölge Eğitim ve AraştırmaHastanesi, Erzurum, Türkiye
}

\section{ÖZET}

Giriş: İnce bağırsağın malign tümörleri tüm gastrointestinal sistem malignitelerinin \%2-3’ ünü oluşturmaktadır. İnce bağırsağın primer malignitelerinin $\% 95$ ' ini adenokarsinomlar oluşturmaktadır. İleri yaşlarda sıklığı artmaktadır. Sıklıkla yerleşim yeri distal duodenum ve proksimal jejunumdur. Tanı genellikle rastlantısal olarak konulmaktadır. Cerrahi en etkin tedavi yöntemidir.

Vaka Sunumu: Bu yazıda, akut strangüle herni sebebiyle acil operasyona alınmış ve operasyon esnasında ileumda tespit edilen tümöral kitle ile ileum adenokarsinomu tanısı konulan 67 yaşında kadın hasta sunulmuştur.

Sonuç: İnce bağırsak adenokanserlerinde en etkin tedavi yöntemi cerrahidir.

Anahtar kelimeler: İnce bağırsak, adenokanser, operasyon

\begin{abstract}
Introduction: Malignant tumors of the small intestine comprise 2-3\% of all gastrointestinal cancers. Adenocarcinomas account for $95 \%$ of primary small intestine malignancies. The prevalence of adenocarcinoma increases with advanced age. They are commonly located in the distal duodenum and the proximal jejunum. They are usually diagnosed coincidentally and are most effectively treated by surgery.

Case Presentation: Here we present a 67-year-old female patient who underwent emergency surgery for acute strangulated hernia during which a tumoral mass was discovered in the ileum, leading to a diagnosis of adenocarcinoma of the ileum.

Conclusion: The most effectively treated method is surgery in small intestine adenocarcinomas.

Keywords: Small intestine, adenocarcinoma, operation
\end{abstract}

Başvuru / Submission: Mart / Mar 31, 2016

Kabul / Acceptance: Nisan / Apr 20, 2016

Yazışma / Correspondence: İç Hastalıkları Kliniği, Erzurum Bölge Eğitim ve Araştırma Hastanesi, Erzurum, Türkiye

E-mail: pinar.tosun@gmail.com

Atıf / Cite: Yıldız F, Taşar PT, Timur Ö, Yıldırım F, Aslan A, Özmen S. Akut karın ağrısında nadir bir sebep: ince bağırsak adenokarsinomu. Fam Pract Palliat Care. 2016;1(3):70-72 


\section{GİRiş}

İnce bağırsağın malign tümörleri oldukça nadirdir, tüm gastrointestinal sistem malignitelerinin \%2-3' ünü oluşturmaktadır. Tahmini yıllık insidansı 2.1/100.000'dir (1). İnce bağırsağın primer malignitelerinde $40^{\prime}$ dan fazla histopatolojik neoplasm türü tanımlanmış olmakla birlikte \%95' ini adenokarsinomlar, gastrointestinal stromal tümörler, karsinoidler ve lenfomalar oluşturmaktadır. Yaşlanmayla birlikte sıklığı artan ince bağırsak adenokarsinomları en sık altıncı ve yedinci dekadlarda görülmekte ve ince bağırsak malignitelerinin yaklaşık \%50' sini oluşturmaktadır $(2,3)$. Sıklıkla yerleşim yeri distal duodenum ve proksimal jejunumdur. Tanı genellikle bası semptomları ve kronik demir eksikliği anemisi ile rastlantısal olarak konulmaktadır. Tanı anında vakaların \%50' sinde metastaz izlenmektedir (4). Tanı özellikle proksimal yerleşimlilerde endoskopik görüntüleme ve biyopsi ile konur. Cerrahi en etkin tedavi yöntemidir (5).

$\mathrm{Bu}$ yazıda, akut inkansere herni sebebiyle acil operasyona alınmış ve operasyon esnasında ileumda tespit edilen tümöral kitle ile ileum adenokarsinomu tanısı konulan 67 yaşında kadın hasta sunulmuştur.

\section{OLGU SUNUMU}

Bir yıldır kabızlık yakınması olan 67 yaşındaki kadın hasta dört aydır özellikle göbek çevresinde yoğunlaşan karın ağrısı şikayeti ile birden çok kez farklı kliniklere başvurmuş. İrritable bağırsak hastalığı tanısı konmuş, semptomatik tedavi ile yakınmalarında gerileme olmamış. Şikayetlerine bulantı, kusma eklenen hasta acil servisimize başvurdu. Fizik muayenesinde; genel durumu orta, vücut 1 sis1 $37^{\circ} \mathrm{C}$, nabz1 $86 / \mathrm{dk}$, solunum say1s1 22/dk, tansiyon arteriyeli $120 / 70 \mathrm{mmHg}$ olarak saptandı. Karın muayenesinde alt kadranlarda ve epigastrik alanda yaygin hassasiyet ve bilateral inguinal alanda ciltten kabarık ele gelen kitle saptandı. Diğer system muayeneleri doğaldı. Özgeçmişinde osteoporozu mevcuttu. Soygeçmişinde özellik yoktu. Laboratuvar tetkiklerinde lökosit sayıs1 15100/ mm3, nötrofil oranı \%89, hemoglobini 13 gram/dl CRP:16,5mg/dl ve diğer biyokimyasal tetkikleri normal olarak saptandı. Yapılan batın Ultrasonografisinde (USG) karın ağrısını açıklayabilecek bulgu mevcut değildi. Yüzeyel inguinal alan USG' sinde bilateral femoral arter-ven medial komşuluklarında $1,5 \mathrm{~cm}$ çaplı cilt altına herniye olmuş direkt inguinal herniye ait görünüm mevcuttu. Hasta akut inkarsere herni ön tanısıyla operasyona alındı. Göbek altı median insizyonla batına girildi. Yapılan batın eksplorasyonunda ileoçekal valvden yaklaşı $150 \mathrm{~cm}$ proksimalde üç $\mathrm{cm}$ çapında lümeni tam tıkayan kitle palpe edildi, Herni kesesi içerisindeki ince bağırsak anslarında strangulasyon bulgusu izlenmedi. Kitlenin ince bağırsak serozasını tam kat invaze ettiği görüldü. Mezodaki kitleleri de içine alacak şekilde geniş ince bağırsak rezeksiyonu ve uçuca çift kat ince bağırsak anastomozu yapıldı. Eksplorasyonun devamında karaciğer ve uzak metastaz izlenmedi. Kitlenin olduğu ince barsak bölümü mezosu dışında patolojik lenf bezi görülmedi. Histopatolojik tanıs1 adenokarsinom, seroza invazyonu pozitif, lenfovasküler invazyon ve cerrahi sınırlarda malignite negatif geldi (Resim 1).
Resim 1.

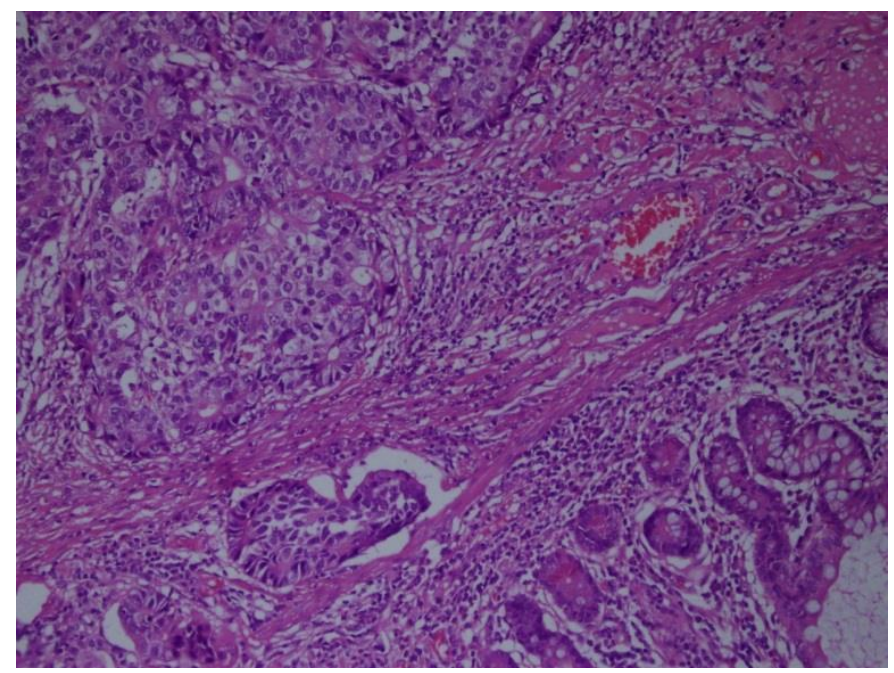

İnce barsağa ait yüzey epiteli komşuluğunda ve altında lamina propriada ve muskularis propriaya ait kas lifleri arasında dağılım gösteren, nükleol belirginliği içeren iri hiperkromatik nükleuslu geniş sitoplazmalı yer yer sitoplazmik sınırları net seçilemeyen atipik pleomorfik hücrelerin ve mitotik figürlerin sırt sırta vermiş gland benzeri dizilim oluşturarak meydana getirdiği neoplastik oluşum izlendi (Resim 2).

Resim 2.

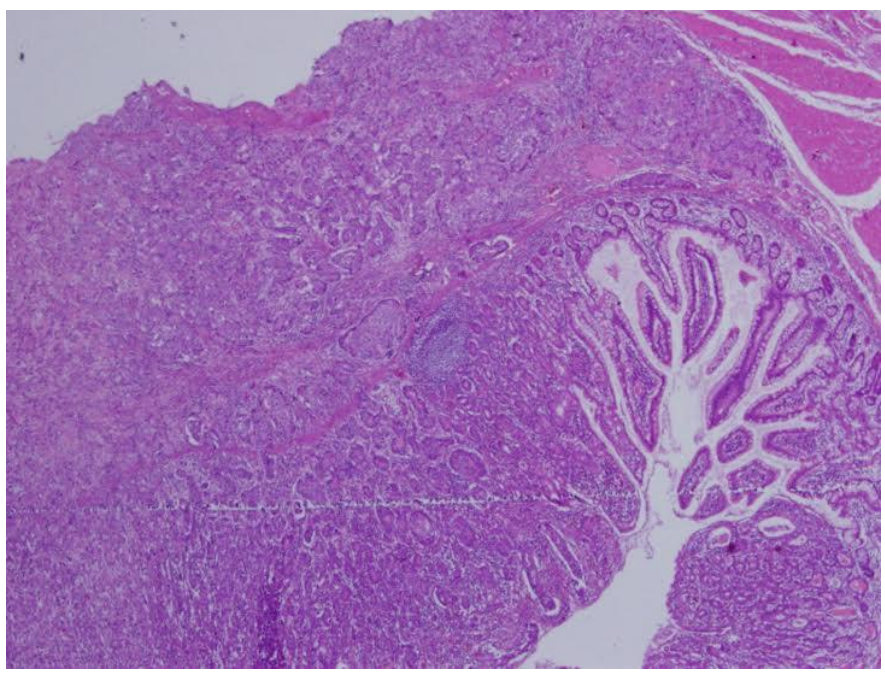

Yapılan Pozitron Emisyon Tomografisinde metastaz açısından bulguya rastlanmadı. Sonrasında onkolojik tedavi verilmeksizin hastanın izlemine ayaktan devam edildi.

\section{TARTIŞMA}

İnce bağırsak uzunluk olarak tüm gastrointestinal sistemin $\% 75^{\prime}$ ini, emilim yüzeyinin $\% 90$ ' a yakın kısmını oluşturmasına rağmen maligniteleri oldukça nadirdir. Bunun nedeni net olmamakla birlikte kalın bağırsağa oranla daha yüksek seviyede $\operatorname{IgA}$ içeriği ve hızlı geçiş süresi sayesinde mukozanın karsinojenlere olan maruziyetinin düşük olması, düşük bakteriyel yük, oksidatif strese daha etkin cevap verilmesi olarak sayllabilir (6-8). 
İnce bağırsak adenokarsinomları sıklıkla duodenumda görülmekle birlikte jejunum ve ileumda da görülmektedir. Ailevi poliposis sendromlarında (Lynch sendromu, Gardner sendromu, Peutz-Jegherssendromu vb.),inflamatuvar barsak hastalıklarında, incebarsaklarda adenokarsinom gelişme riski artmıştır (9). Hastalığın spesifik klinik bulgularının olmayışı sebebiyle hastalar genellikle ileri evrede tanı almaktadır. Klinik olarak sıklıkla kanama ve obstrüksiyon görülmektedir. Hastalığın tanısında sıklıkla kullanılan görüntüleme yöntemi oral ve/ veya intravenöz kontrastlı bilgisayarlı tomografidir (10). Endoskopik görüntüleme yöntemlerinin (çift balon entereskopi, video kapsül endoskopi gibi) tan1 da kullanımlarının sıklığı artmaktadır (11). Ancak bizim vakamızda da olduğu gibi hastaların çoğu cerrahi eksplorasyon esnasında tanı almaktadır. Her ne kadar tanı anında vakaların \%50' sinde metastaz saptanmış olsa da (4) bizim vakamızda metaztaz lehine bulgu saptanmamıştır.

Tedavide halen güncel yaklaşım lenfadenektomi ile birlikte sağlam cerrahi sınırın sağlandığı geniş rezeksiyondur. Tümörün distal ileum yerleşimi durumunda radikal sağ hemikolektomi sağlam cerrahi sınır elde edilmesi açısından önerilmektedir. Adjuvan kemoterapinin tedavideki yeri tartışmalı olup hastalığın evresi ve yararı dikkate alınarak uygulanabileceği belirtilmiştir (12).

\section{SONUÇ}

Sonuç olarak; incebağırsağın primer maligniteleri nadir görülmektedir, semptomlarının olmaması ve rutin radyolojik görüntülemelerin normal olması sebebiyle tanıda güçlükler yaşanmaktadır. Kronik ve/veya akut karın ağrısı varlığı ve proksimal seviyeli intestinal obstrüksiyonlarda ince barsak adenokarsinomları da akılda tutulmalı ve mümkün olduğunca küratif cerrahi uygulanmalıdır.

Çıkar çatışması: Bulunmamaktadır.

\section{Finansal destek: Bulunmamaktadır.}

\section{KAYNAKLAR}

1. Shenoy S. Primary small-bowel malignancy: update in tumor biology, markers, and management strategies. Journal of gastrointestinal cancer 2014; 45: 421-30.

2. Hatzaras I, Palesty JA, Abir F, et al. Small-bowel tumors: epidemiologic and clinical characteristics of 1260 cases from the connecticut tumor registry. Archives of surgery 2007; 142: 229-35.

3. Honda W, Ohmiya N, Hirooka Y, et al. Enteroscopic and radiologic diagnoses, treatment, and prognoses of smallbowel tumors. Gastrointestinal endoscopy 2012; 76: 344 54.

4. Talamonti MS, Goetz LH, Rao S, Joehl RJ. Primary cancers of the small bowel: analysis of prognostic factors and results of surgical management. Archives of surgery 2002; 137: 564-70; discussion 70-1.

5. Howdle PD, Jalal PK, Holmes GK, Houlston RS. Primary small-bowel malignancy in the UK and its association with coeliac disease. QJM : monthly journal of the Association of Physicians 2003; 96: 345-53.

6. Reynolds I, Healy P, McNamara DA. Malignant tumours of the small intestine. The surgeon : journal of the Royal Colleges of Surgeons of Edinburgh and Ireland 2014; 12 : 263-70.

7. Cerutti A, Rescigno M. The biology of intestinal immunoglobulin A responses. Immunity 2008; 28: 740-50.

8. Sanders LM, Henderson CE, Hong MY, et al. Pro-oxidant environment of the colon compared to the small intestine may contribute to greater cancer susceptibility. Cancer letters 2004; 208: 155-61.

9. Aparicio T, Zaanan A, Svrcek M, et al. Small bowel adenocarcinoma: epidemiology, risk factors, diagnosis and treatment. Digestive and liver disease : official journal of the Italian Society of Gastroenterology and the Italian Association for the Study of the Liver 2014; 46: 97-104.

10. Horton KM, Fishman EK. The current status of multidetector row CT and three-dimensional imaging of the small bowel. Radiologic clinics of North America 2003; 41: 199-212.

11. Kulesza J, Meszka M, Rykala C, Pawlak J. Adenocarcinoma of the small bowel - a case report. Polskiprzegladchirurgiczny 2014; 86: 285-8.

12. Overman MJ, Kopetz S, Lin E, Abbruzzese JL, Wolff RA. Is there a role for adjuvant therapy in resected adenocarcinoma of the small intestine.Actaoncologica 2010; 49: 474-9. 